\title{
O PAPEL DO PESQUISADOR NA METODOLOGIA DE INVESTIGAÇÃO CIENTÍFICA: A IMPORTÂNCIA DA PESQUISA CIENTÍFICA QUALITATIVA OU QUANTITATIVA
}

\section{ARTIGO ORIGINAL}

SORTE, Mágela Domingues Boa ${ }^{1}$

COÊLHO, Márcio Wendel Santana ${ }^{2}$

SORTE, Mágela Domingues Boa. COÊLHO, Márcio Wendel Santana. O papel do pesquisador na metodologia de investigação científica: a importância da Pesquisa Científica Qualitativa ou Quantitativa. Revista Científica Multidisciplinar Núcleo do Conhecimento. Ano 04, Ed. 10, Vol. 09, pp. 102-111. Outubro de 2019. ISSN: 2448-0959,

Link de acesso: https://www.nucleodoconhecimento.com.br/educacao/papel-do-pesquisador

\section{RESUMO}

O presente trabalho tem por objetivo fazer um levantamento breve a respeito do papel do pesquisador referente à metodologia de pesquisa quantitativa e qualitativa. $\mathrm{O}$ trabalho buscou apresentar definições sucintas sobre o papel do pesquisador e a diferenciação entre abordagem metodológica qualitativa e quantitativa. Para tanto, alguns critérios são fornecidos para julgar a pertinência do caminho percorrido pelos pesquisadores que optam pela metodologia qualitativa ou quantitativa. $\mathrm{O}$ artigo tem

\footnotetext{
${ }^{1}$ Mestrado em Ciências da Educação, Pós-graduação em Metodologia e Ensino e Pesquisa na educação em Matemática e Física, Docência Universitária, Gestão Escolar e Orientação Educacional e Especialista em Ciências da Educação e Graduação Licenciatura em Matemática.

${ }^{2}$ Graduado em Pedagogia, Especialista em: Pedagogia Escolar \& Psicologia Escolar, Mestra em Ciências da Educação e Doutor em Ciências da Saúde \& Psicanálise Clínica e Doutor em Ciências da Educação.
} 
como a incumbência, fornecer pequenos subsídios àqueles que pretendem elaborar seus projetos de investigação qualitativa ou quantitativa. Dessa forma, apresenta definições concernentes e diferenças entre as metodologias supracitadas, bem como, o papel do pesquisador diante da abordagem que melhor responda às suas inquietações. A partir das reflexões apresentadas fica evidente a relevância da definição e escolha da metodologia de pesquisa, seja Quantitativa ou Qualitativa, tendo em vista que, ambas são ferramentas necessárias na realização de cada modalidade de investigação.

Palavras Chave: Pesquisa quantitativa, pesquisa qualitativa, pesquisador.

\section{INTRODUÇÃO}

Quando ouvimos falar ou pensamos em pesquisa científica logo nos vem à cabeça vários questionamentos, tais como: a busca por algo novo, referente aos avanços tecnológicos, baseando-se em estratégias e metodologias adequadas às inquietações dos seus respectivos pesquisadores e sua importância ou contribuição para a sociedade como um todo.

Tendo em vista a importância do tema deste trabalho, decidimos não optar por uma das duas abordagens: seja Quantitativa ou Qualitativa, de maneira que, a definição das duas se faz interessante saber para eventuais trabalhos futuros. Dessa forma, no corpo deste trabalho, discorreremos sobre o papel do pesquisador frente à realização de uma investigação acadêmica e a definição das abordagens quantitativa e qualitativa. Ao expor as peculiaridades essenciais de cada abordagem, apresentamos também, de maneira bem sintetizada, as etapas para a produção da pesquisa, a ser feita.

$\mathrm{Na}$ elaboração e desenvolvimento do seu trabalho, o pesquisador deve se preocupar com os instrumentos necessários para alcançar os objetivos propostos, de maneira que a base metodológica; alicerce da sua pesquisa seja bem definida. Nesse sentido, uma pesquisa bem estruturada opta por uma metodologia de pesquisa que melhor possibilita uma investigação concisa, coerente e comprometida com a problemática 
em estudo. Além disso, para se pensar na escolha da metodologia de trabalho em uma pesquisa é necessário muito empenho e estudo, pois, o objetivo nesse processo é adquirir um conhecimento abrangente das possibilidades e das perspectivas daquilo que se quer saber. Dessa forma, a adequação entre o planejamento do trabalho e a realidade do fenômeno estudado precisam trilhar caminhos seguros, garantindo com isso, o máximo de precisão possível.

Tendo em vista que a produção e o registro da ciência são de fundamental importância para a conservação e preservação de resultados, observações, cálculos, teorias e novas possibilidades dando margem à críticas, aceitação ou refutação.

Assim sendo, o presente artigo tem como objetivo contribuir modestamente com a academia e apresentar, de forma sintetizada, um pequeno estudo sobre o papel do pesquisador na metodologia de abordagens Quantitativa ou Qualitativa. Metodologicamente, pode-se assumir que as reflexões aqui apresentadas emergem de uma breve revisão teórica empreendida pelos autores supracitados e de uma necessidade de sua autora.

\section{O PAPEL DO PESQUISADOR}

Para refletirmos a cerca do papel do pesquisador se faz necessário definirmos o que seja pesquisa. Segundo Demo (2000), a pesquisa apresenta-se como a instrumentação teórico-metodológica na aquisição do conhecimento, isso, na condição de princípio científico. Já para Luna (2000), a essência da pesquisa visa a produção de um conhecimento novo, relevante e socialmente confiável. O conceito de novo para a autora significa neste contexto, um conhecimento que preenche uma lacuna importante no contexto disponível em determinada área do saber. Nesse sentindo, a investigação é a uma construção de conhecimento inovado, a construção de novas técnicas, a criação ou exploração de novas realidades, levando-se em conta que os fenômenos se renovam e modificam com o tempo.

Conforme o dicionário Aurélio (Ferreira, 1986), o estudo é uma indagação ou busca minuciosa para averiguação da realidade; investigação, inquirição. Além disso, 
também significa "investigação e estudo, minudentes e sistemáticos, com o fim de descobrir ou estabelecer fatos ou princípios relativos a um campo qualquer do conhecimento". Ter conhecimento dessas definições nos ajuda a compreender a investigação como uma ação de ciência da existência, um processo de investigação mais detalhado e organizado que nos leva a melhor aquisição de conhecimento de maneira real e natural.

Partindo dessa premissa, é muito importante compreender a investigação como um processo de produção de conhecimentos para a compreensão de uma dada realidade, pois o conhecimento nos auxilia na interpretação da realidade vivida. Para Minayo:

Entendemos por pesquisa a atividade básica da Ciência na sua indagação e construção da realidade. É a pesquisa que alimenta a atividade de ensino e a atualiza frente à realidade do mundo. Portanto, embora seja uma prática teórica, a pesquisa vincula o pensamento e ação. Ou seja, nada pode ser intelectualmente um problema, se não tiver sido, em primeiro lugar, um problema da vida prática (MINAYO, 2002, p. 17).

Com isso, a pesquisa por mais abstrata que possa parecer, tem a função de interpretar o que vivemos conforme a nossa realidade e ou necessidades. Como afirma Santos (1989), a investigação é uma prática social de conhecimento. Dessa forma, autor ao conferir à pesquisa o objetivo último do conhecimento para a vida social, reforça o caráter social da mesma enquanto atividade da vida prática. Por outro lado, temos definições de pesquisa que a relacionam com o método e também com a sistematização dos conhecimentos.

Por outro lado, o conhecimento científico é produzido em sociedade e esta produção e sua veiculação estão interligadas às formas como certas relações sociais e de poder se estruturam. A busca pela verdade nos dá suporte quanto às crenças e as representações específicas sobre a construção de conhecimentos científicos. Dessa forma é que assistimos no campo do conhecimento humano a impregnação de determinados modelos investigativos que predominaram em todas as áreas das ciências e, observar com precisão e controle, bem como, mensurá-los passa a ser uma condição de cientificidade. 
Uma pesquisa científica constitui-se de um processo de investigação minuciosa, com objetivos definidos, e que exige rigor, seriedade e método. Segundo Minayo (2002), a pesquisa cientifica deve acontecer em meio a uma relação inerente a dualidades entre a oposição e a complementaridade entre o universo natural e o social, bem como, o pensamento e a base material, compreendida na abordagem Dialética, pois conforme Minayo:

Ela se propõe a abarcar o sistema de relações que constrói o modo de conhecimento exterior ao sujeito, mas também as representações sociais que traduzem o mundo dos significados. A Dialética pensa a relação da quantidade como uma das qualidades dos fatos e fenômenos. Busca encontrar, na parte, a compreensão e a relação com o todo e a interioridade e a exterioridade como constitutivas dos fenômenos, (MINAYO, 2002, p.24).

O estudo científico desbrava a realidade, buscando estabelecer as relações de causa e efeito que a compõe, tendo em vista que, com os dados coletados e as conclusões alcançadas, se pode chegar ao conhecimento desejado. Gil (2007) acredita que o estudo científico é como um procedimento sistemático e racional e que tem como objetivo possibilitar aos problemas propostos, as respostas. Para ele, a pesquisa é uma investigação que se constitui mediante um processo composto por diversas etapas, que vai desde a formulação do problema até a apresentação e discussão dos resultados.

Assim, nos ancoramos na fundamentação de Oliveira (2011) onde afirma que para o conhecimento científico ser aceito, ele deve emanar de uma investigação possível de comprovação e validade dos seus resultados, bem como, no processo da sua execução, respeitou os métodos estabelecidos.

A metodologia científica é fundamental para validar as pesquisas e seus resultados serem aceitos. Na investigação científica, o conhecimento científico é produzido através de procedimentos. Como aborda Fonseca.

O conhecimento científico é produzido pela investigação científica, através de seus métodos. Resultante do aprimoramento do senso comum, o conhecimento científico tem sua origem nos seus procedimentos de verificação baseados na metodologia científica. É um 
conhecimento objetivo, metódico, passível de demonstração e comprovação. O método científico permite a elaboração conceitual da realidade que se deseja verdadeira e impessoal, passível de ser submetida a testes de falseabilidade. Contudo, o conhecimento científico apresenta um caráter provisório, uma vez que pode ser continuamente testado, enriquecido e reformulado. Para que tal possa acontecer, deve ser de domínio público (FONSECA, 2002, p. 11).

Dessa forma, o conhecimento científico visa fornecer explicações sistemáticas através de investigação e emerge da necessidade de encontrar soluções para determinado problema.

Para tanto numa pesquisa científica é notável a busca por autores que propõem caminhos para a busca do conhecimento, que respondem e discutem as questões de investigação levantadas através da problemática. Dessa forma, para que a pesquisa se intitule como "científica", se faz necessário que esta seja desenvolvida de forma organizada e sistemática, seguindo um planejamento previamente estabelecido pelo pesquisador.

Através do planejamento da pesquisa ficam estabelecidos os caminhos a serem percorridos na investigação de um estudo, seja ele de qualquer natureza. Partindo dessa premissa, pesquisador é aquele profissional que faz pesquisa, quer saber a resposta de uma pergunta e elabora uma resposta. É da inquietação de um pesquisador que parte o seu interesse por respostas que poderão ser obtidas através de um trabalho científico resultante da realização e da dedicação a uma pesquisa para qualquer que seja a sua finalidade. A pesquisa acontecerá mediante um planejamento bem estruturado. Portanto, ao elaborar o seu projeto de pesquisa, o pesquisador deve ser coerente, ter consciência, objetividade, originalidade, confiabilidade e criatividade.

Segundo Kant (1998), o conhecimento científico acontece mediante a interligação consistente entre a teoria e a prática ao afirmar que: "os conceitos sem as intuições são vazios, e as intuições sem os conceitos são cegas". Remetendo-nos à crença de que esta afirmação reforça a ideia da passividade de leis, sistemas e teorias, existentes no racionalismo e o empirismo, formam o conhecimento científico. 
$\mathrm{Na}$ versão de Demo (1996), a investigação é considerada como uma atividade cotidiana, vista como uma indagação sistemática, crítica e criativa, uma atitude, uma intervenção competente ou um diálogo crítico permanente com o cotidiano em sentido conceitual e funcionalista.

Segundo Gil (1999), a investigação é uma estratégia categórica e comedida do avanço da metodologia científica e tem um temperamento usual, tendo esta a finalidade principal da pesquisa, mostrar as respostas para os problemas por intermédio de um sistema específico. Vai além, ao afirmar que a investigação é uma reunião de intervenções apresentadas para solucionar problema, tendo como sustentação, processos lógicos e ordenados. Enfim, quando necessitamos de solução para uma problemática, a investigação é a chave que nos dará a solução para os nossos dilemas.

Partindo dessa premissa, o papel do pesquisador é muito importante, tendo em vista que o mesmo tem, entre outros passos, definir a metodologia da investigação desejada. Com isso, dependendo da inquietação ou problemática, é que o investigador opta por uma metodologia de pesquisa.

\section{ABORDAGEM QUANTITATIVA OU QUALITATIVA}

Abordagens metodológicas que englobam as pesquisas são classificadas em dois grupos distintos: o quantitativo e o qualitativo. O primeiro obedece ao padrão clássico (positivismo) enquanto o outro segue o padrão chamado alternativo.

Pesquisa Quantitativa: expressa e traduz em valores numéricos o conceito e os dados para catalogá-los e examiná-los, julga que tudo pode ser representado po quantidades numéricas. Para tanto o processo requisita o uso de recursos e técnicas estatísticas, ou seja, parte do princípio de que essa modalidade solicita a aplicação da análise de dados como, percentagens, médias aritméticas, mediana, grau de equiparação, entre outros. A Pesquisa Quantitativa tem como objetivo aferir os pareceres manifestados pelos entrevistados e, neste caso, o questionário representa um dos meios mais eficazes para testar de forma precisa, as hipóteses levantadas. O questionário pode 
ser elaborado de questões fechadas, apresentando um universo de alternativas de respostas com a intenção de se obter as respostas que melhor representam o parecer da pessoa entrevistada. Esboçando de forma precisa o que se deseja, tal procedimento garante aproximação de entendimento por parte dos entrevistados, o que contribui para a eficácia e precisão dos resultados.

Com isso, as pesquisas quantitativas são mais adequadas para apurar opiniões e atitudes explícitas e conscientes dos entrevistados, pois utilizam instrumentos quantificáveis. A abordagem quantitativa oferece duas diferentes possibilidades de se realizar pesquisa: a pesquisa empírica e as pesquisas de campo.

Pesquisa Qualitativa: conceitua que a conexão prática entre o mundo concreto e o indivíduo, ou seja, admite uma ligação inseparável entre o universo objetivo e a subjetividade do indivíduo impossível de ser transposto em valores numéricos. Com isso, a incumbência da interpretação das ocorrências é elementar no método da pesquisa qualitativa. A pesquisa qualitativa, portanto, não requer a utilização de procedimentos estatísticos. Nesse caso, o meio proveniente é a fonte direta para levantamento de dados e o pesquisador é a ferramenta-chave. Tem caráter descritivo, em que os investigadores inclinam a interpretação dos seus dados de modo indutivo e também, exploratórios, pois estimulam os entrevistados a darem o seu parecer livremente sobre algum tema, objeto ou conceito. O significado e seu processo são os pontos principais de interpelação.

A abordagem qualitativa oferece três diferentes possibilidades de se realizar pesquisa: a pesquisa documental, a pesquisa direcionada e a etnografia. Ela faz emergir aspectos subjetivos, atinge motivações não explícitas, ou mesmo não conscientes, de forma espontânea.

De qualquer forma, uma vez definido o tema da pesquisa, o pesquisador deve escolher realizar uma pesquisa qualitativa ou uma quantitativa, tendo em vista que, uma não substitui a outra, elas se complementam. 
Mediante o descrito, pode-se considerar que tanto a metodologia quantitativa quanto a qualitativa, ambas são modalidades incapazes de serem consideradas excludentes, ao contrário, apenas se distinguem por apresentarem funções específicas, mas que se completam.

\section{CONSIDERAÇÕES FINAIS}

A abordagem qualitativa da pesquisa permite 0 aprofundamento da compreensão, busca aspectos da realidade para explicar o porquê dos fatos. Conforme Gerhardt e Silveira (2009), a abordagem qualitativa preocupa-se, portanto, com aspectos reais não quantificáveis, centrando-se na compreensão e explicação da dinâmica das relações sociais.

Uma técnica mais eficaz de se realizar uma pesquisa qualitativa é usando o método de entrevistas, que proporciona trazer dados da realidade, do contexto social o qual o entrevistado está inserido para quantificá-lo depois e aprofundar os já conhecidos.

Já a abordagem quantitativa possibilita representatividade numérica através de tabelas e/ou gráficos, os quais possibilitarão visualizar pontos fortes e fracos. Como estabelecido por Fonseca.

A aplicação de questionários a um grupo de investigados permite quantificar os resultados que poderão ser expressos em tabelas e gráficos, permitindo assim, melhor compreensão dos dados coletados.

Enfim, as abordagens podem ser complementares e adequadas para minimizar a subjetividade e aproximar o pesquisador da causa do estudo, respondendo as principais críticas, seja ela qualitativa ou quantitativa respectivamente, proporcionando maior confiabilidade aos dados pesquisados. Em suma, é no conhecimento científico que o investigador encontra sua busca pelas verdades ou hipóteses levantadas; sendo nele ou por meio dele que descobre respostas e têm suas inquietações, intuições e ou experimentações comprovadas. 


\section{REFERÊNCIAS}

DEMO, Pedro. Pesquisa e construção de conhecimento. Rio de Janeiro: Tempo Brasileiro. 1996.

- Pesquisa e Construção de conhecimento: metodologia científica no caminho de Habernas. Rio de Janeiro: Tempo Brasileiro, 2000, p. 125.

FERREIRA, A. B. H. Novo dicionário da Língua Portuguesa. 2. ed. Rio de Janeiro: Nova Fronteira, 1986.

FONSECA, J. J. S. Metodologia da pesquisa científica. Fortaleza: UEC, 2002.

GERHARDT, Tatiana Engel; SILVEIRA, Denise Tolfo (organizadoras). Métodos de Pesquisa. $1^{\underline{a}}$ Ed. Porto Alegre: Editora da UFRGS, 2009.

GIL, Antonio Carlos. Como elaborar projetos de pesquisa. 4. ed. São Paulo: Atlas, 2007.

GIL, Antônio Carlos. Métodos e técnicas de pesquisa social. 6. Ed. São Paulo: Atlas, 1999.

KAUARK, Fabiana; MANHÃES, Fernanda Castro; MEDEIROS, Carlos Henrique. Metodologia da pesquisa: guia prático. Itabuna: Via Litterarum, 2010.

LUNA, Sergio Vasconcelos de. Planejamento de Pesquisa: uma introdução. São Paulo: Ed. Educ, 2000,108 p.

MINAYO, Maria Cecília de Souza. Pesquisa Social: teoria, método e criatividade. Petrópolis, Vozes, 2002.

O desafio do conhecimento. 11 ed. São Paulo: Hucitec, 2008.

OLIVEIRA, Maxwell Ferreira de. Metodologia científica: um manual para a realização de pesquisas em Administração. Catalão: UFG, 2011. 
SANTOS, B. S. Introdução à uma ciência pós-moderna. Rio de Janeiro: Graal, 1989.

Enviado: Setembro, 2019.

Aprovado: Outubro, 2019. 